\title{
Adverse Effects of Aromatase Inhibition on the Brain and Behavior in a Nonhuman Primate
}

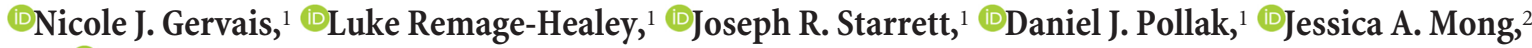 \\ and ${ }^{\circledR}$ Agnès Lacreuse ${ }^{1}$ \\ ${ }^{1}$ Department of Psychological and Brain Sciences and Center for Neuroendocrine Studies, University of Massachusetts, Amherst, Massachusetts 01003 \\ and ${ }^{2}$ Department of Pharmacology, University of Maryland School of Medicine, Baltimore, Maryland 21201
}

Breast cancer patients using aromatase inhibitors (AIs) as an adjuvant therapy often report side effects, including hot flashes, mood changes, and cognitive impairment. Despite long-term use in humans, little is known about the effects of continuous AI administration on the brain and cognition. We used a primate model of human cognitive aging, the common marmoset, to examine the effects of a 4-week daily administration of the AI letrozole ( $20 \mu \mathrm{g}$, p.o.) on cognition, anxiety, thermoregulation, brain estrogen content, and hippocampal pyramidal cell physiology. Letrozole treatment was administered to both male and female marmosets and reduced peripheral levels of estradiol (E2), but unexpectedly increased E2 levels in the hippocampus. Spatial working memory and intrinsic excitability of hippocampal neurons were negatively affected by the treatment possibly due to increased hippocampal E2. While no changes in hypothalamic E2 were observed, thermoregulation was disrupted by letrozole in females only, indicating some impact on hypothalamic activity. These findings suggest adverse effects of AIs on the primate brain and call for new therapies that effectively prevent breast cancer recurrence while minimizing side effects that further compromise quality of life.

Key words: anxiety; aromatase inhibitors; hippocampal physiology; neuroestradiol; spatial working-memory; thermoregulation

Significance Statement

Aromatase inhibitors (AIs) are used as an adjuvant therapy for estrogen-receptor-positive breast cancer and are associated with side effects, including hot flashes, depression/anxiety, and memory deficits severe enough for many women to discontinue this life-saving treatment. AIs are also used by men, yet sex differences in the reported side effects have not been systematically studied. We show that AI-treated male and female marmosets exhibit behavioral changes consistent with these CNS symptoms, as well as elevated hippocampal estradiol and compromised hippocampal physiology. These findings illustrate the need for (1) a greater understanding of the precise mechanisms by which AIs impact brain function and (2) the development of new treatment approaches for breast cancer patients that minimize adverse effects on the brain.

\section{Introduction}

Estrogens are synthesized by the conversion of testosterone (T) through the enzyme aromatase. To prevent this conversion,

Received Feb. 7, 2018; revised Nov. 12, 2018; accepted Nov. 17, 2018.

Author contributions: N.J.G. wrote the first draft of the paper; L.R.-H., J.R.S., D.J.P., J.A.M., and A.L. edited the paper. N.J.G., L.R.-H., J.A.M., and A.L. designed research; N.J.G., L.R.-H., J.R.S., D.J.P., J.A.M., and A.L. performed research; N.J.G., L.R.-H., J.R.S., and D.J.P. analyzed data; N.J.G., L.R.-H., and A.L. wrote the paper.

This work was supported in part by National Institutes of Health Grant R01AG046266 to A.L. and Grant R01NS082179 to L.R-H. We thank John Meitzen and Geng-Lin Li for helpful discussions; Matthew LaClair, Kathryn Workman, Catherine de Bournonville, and Garrett Scarpa for technical support and help with data collection; the University of Massachusetts animal care team for dedicated work to the animals; Jerrold Meyer as well as the Psychology shop for technical assistance.

The authors declare no competing financial interests.

Correspondence should be addressed to Nicole J. Gervais at nicole.gervais@utoronto.ca.

N.J. Gervais' present address: Department of Psychology, University of Toronto, 100 Saint George Street, Toronto, Ontario M5S 363, Canada.

https://doi.org/10.1523/JNEUROSCI.0353-18.2018

Copyright $\odot 2019$ the authors $\quad 0270-6474 / 19 / 390918-11 \$ 15.00 / 0$ women with estrogen receptor (ER)-dependent breast cancers are often given aromatase inhibitors (AIs) as an adjuvant therapy for many years (Burstein et al., 2014; Chumsri et al., 2016). AIs are associated with side effects that impair quality of life, including insomnia (Desai et al., 2013), hot flashes (Rand et al., 2011), depression (Chumsri et al., 2016), and memory deficits (Bender et al., 2007; Blaustein, 2017; but see Ganz et al., 2016). For example, reduced hippocampal (HPC) activity and increased PFC activity, along with slightly diminished memory, were reported in women taking letrozole (Bayer et al., 2015). Memory deficits in women have also been reported in other studies (e.g., Collins et al., 2009), but not all (for review, see Lee et al., 2016), and one study in older men showed improved spatial memory following AI treatment (Cherrier et al., 2005). However, the mechanisms by which AIs give rise to these CNS symptoms remain unclear as studies in humans often lack proper controls and are hampered by confounds, such as concurrent chemotherapy/radiotherapy 
treatment, stress, and disease stage. AI use is also relevant in men with prostate (Dias et al., 2016) and breast cancer (Fentiman, 2018), yet no systematic analysis of sex differences has been conducted on the above-mentioned side effects.

Experimental studies in appropriate animal models are needed to complement those in humans as they offer the advantage of including appropriate control groups in the absence of the confounds listed above. Aromatase is expressed in several brain regions (Naftolin et al., 1972; Cornil, 2017), including those involved in processes regulating thermoregulation (i.e., hypothalamus; Roselli, 2013), emotion (i.e., amygdala; Roselli, 2013), and cognition (HPC, cortex; Hojo et al., 2004; Vahaba and Remage-Healey, 2015). Evidence from rodent and bird studies suggests that aromatase inhibition results in HPC-dependent memory deficits. For example, aromatase $\mathrm{KO}(\mathrm{ArKO})$ male and female mice show impaired spatial reference memory compared with WT (Martin et al., 2003); inhibiting aromatase in the HPC reduces novelty preference in ovariectomized (OVX) female mice (Tuscher et al., 2016) and decreases spatial learning and memory in male zebra finches (e.g., Bailey et al., 2017). These effects may be due to synaptic changes in the HPC, as estradiol (E2)-synthesis inhibition reduces the number of spine synapses in the HPC in vitro (Kretz et al., 2004) and in vivo in OVX mice (Zhou et al., 2010), potentially by destabilizing the spine cytoskeleton (Vierk et al., 2014). Aromatase inhibition in HPC slices also results in a failure to induce LTP in female, but not male, mice (Vierk et al., 2012). These studies have focused on HPC-dependent memory and physiology, without addressing potential changes in thermoregulation and mood. Further, these studies were conducted in animal models phylogenetically distant from humans.

The aim of the present study was to determine whether continuous neuroestradiol synthesis inhibition in a nonhuman primate, the common marmoset, produces adverse effects similar to those reported in humans. The structural and functional organization of the marmoset brain is comparable with the rhesus or human brain (Chaplin et al., 2013). Marmosets also share many similarities with humans in sleep and thermoregulation patterns (Hoffmann et al., 2012; Gervais et al., 2016), cognitive ability (Spinelli et al., 2004; Yamazaki et al., 2016), and anxiety profiles (Barros et al., 2008; Galvão-Coelho et al., 2008), implicating this species as a strong translational model for studying AI effects on the CNS. Aromatase is expressed in the HPC of marmosets (Wehrenberg et al., 2001), suggesting that local estrogen synthesis occurs in this primate, as in humans (for review, see Azcoitia et al., 2011). We hypothesized adverse effects of daily AI treatment on the brain, behavior, and memory, including reduced excitability of CA1 neurons, increased anxiety, thermodysregulation, and memory impairment. When possible, attempts were made to identify sex differences.

\section{Materials and Methods}

Subjects. Sixteen (males: $n=9$; females: $n=7$ ) middle- to older-aged common marmosets (Callithrix jacchus; age: 5.5-9.5 years old) weighing 332-511 g participated in the study. Marmosets have an average lifespan of $\sim 12$ years and show signs of aging by the age of 8 (Tardif et al., 2011). They were gonadectomized (GDX) $\sim 3$ years before the start of the experiment. The marmosets were housed in opposite-sex pairs $(n=14)$, except 2 males that were housed together. The cages were made of stainless-steel mesh $(101 \times 76.2 \times 78.74 \mathrm{~cm})$ and contained perches, platforms, one nest box, and hammocks to promote species-typical behavior, including foraging, scent-marking, and climbing. Animals were maintained under a $12 \mathrm{~h}$ light cycle (lights on at 8:30 A.M.), and the ambient temperature set at $\sim 27^{\circ} \mathrm{C}$, and humidity at $\sim 50 \%$. Marmosets were fed Mazuri Callitrichid High Fiber Diet 5M16 (Purina Mills) supplemented with a variety of fresh fruit, nuts, and mealworms. Fruit and nuts were provided twice daily (8:00 A.M. to 9:00 A.M. and 1:00 P.M. to 3:00 P.M.), and water was available ad libitum. The monkeys were provided with daily enrichment, including foraging tubes and a variety of toys. The animals were cared for in accordance with the guidelines published in the Guide for the care and use of laboratory animals, eighth edition. The studies were approved by the University of Massachusetts Institutional Animal Care and Use Committee.

Experimental design. Behavioral, spatial memory performance and facial temperature measures were collected to address whether continuous administration of oral letrozole to middle-aged GDX marmosets mimics the CNS symptoms reported by women taking AIs. Brain tissues were analyzed for E2 content and HPC pyramidal cell physiology to investigate effects of letrozole on the brain. Urine analysis was conducted to determine effects of letrozole on peripheral levels of E2, T, and cortisol. Half the marmosets (females: $n=4$; males: $n=4$ ) were fed $20 \mu \mathrm{g}$ of letrozole mixed in $\sim 0.3 \mathrm{~g}$ pudding (Jell-O) daily for 4 weeks. The letrozole dose was determined based on the recommended dose for women $(2.5 \mathrm{mg} / \mathrm{d})$ (Bayer et al., 2015). The remaining marmosets (females: $n=3$; males: $n=5$ ) received pudding without the drug. Group assignment was pseudorandom, with one member of each pair assigned to letrozole and the other to vehicle. Both treatment groups were matched based on age and sex. Marmosets were administered the spatial working memory test (i.e., delayed matching-to-position task [DMP]) daily for $5 \mathrm{~d}$ before the start of the drug treatment, and again during the fourth week of treatment. During the final treatment week, experimenters also collected urine for later hormone analysis, video-recorded spontaneous behaviors of each marmoset in their home cage, and administered the thermal challenge. The thermal challenge was designed after procedures used in postmenopausal women to induce hot flashes via application of a heating pad to the abdomen (Freedman, 1989; Sievert et al., 2002). After euthanasia, electrophysiological recordings were conducted on pyramidal cells in the CA1, and E2 levels were analyzed in several brain regions. All experimenters were blind to group membership.

Treatment administration. Previous animal studies used a route of administration and AI dose that differed from those used by breast cancer patients. In the present study, attempts were made to match route (i.e., oral) and dose to that of humans. The letrozole dose was determined based on the recommended dose for women $(2.5 \mathrm{mg} / \mathrm{d}$ ) (Bayer et al., 2015). After a 1 week baseline period, half the marmosets (females: $n=4$; males: $n=4$ ) were fed $20 \mu$ g of letrozole mixed in $\sim 0.3$ g pudding (Jell-O) daily for 4 weeks. The remaining marmosets (females: $n=3$; males: $n=5$ ) received pudding without the drug. Group assignment was pseudorandom, with one member of each pair assigned to letrozole and the other to vehicle. Both treatment groups were matched based on age and sex.

Urine collections and assay. While ovaries are the major source of peripheral E2, previous studies have shown that ovariectomy does not completely abolish E2 levels in the marmoset (Barnett et al., 2006; Lacreuse et al., 2014), suggesting alternate tissues continue producing this hormone. Because AI use should further deplete any E2 synthesis in OVX females and GDX males, peripheral E2 levels were analyzed at the end of the treatment phase. Some studies have also reported increased $\mathrm{T}$ following AI use (Taylor et al., 2017), and so T levels were also assessed. Cortisol was also measured as a negative control, as there is little evidence that AIs should influence cortisol synthesis (Bajetta et al., 1999; Rossi et al., 2009). A few minutes before lights on (i.e., 8:30 A.M.), marmosets entered a stainless-steel transport box $(34.1 \times 20.65 \times 30.8 \mathrm{~cm})$ attached to their home cage. They were released once they had urinated, or $15 \mathrm{~min}$ had elapsed. Urine was collected using a disposable transfer pipette and placed in a microcentrifuge tube, then spun for $5 \mathrm{~min}$ at 14,000 rpm. The supernatant was then transferred to a separate tube before being stored at $-20^{\circ} \mathrm{C}$. Samples collected were analyzed for these three hormones using enzyme immunoassay (EIA) by the Endocrine BioServices Laboratory at the University of Nebraska at Omaha. 
Table 1. Marmoset behavioral ethogram

\begin{tabular}{ll}
\hline Behavior & Definition \\
\hline Agitated locomotion & $\begin{array}{c}\text { Rapidly moving between locations with an exaggerated gait; } \\
\text { tail extended or arched } \\
\text { Stationary behavior involving continuous head movements } \\
\text { while scanning environment } \\
\text { Inactive alert }\end{array}$ \\
$\begin{array}{l}\text { Rubbing sternal (tummy) or anogenital area } \\
\text { (more commonly) over surface/substrate }\end{array}$ \\
$\begin{array}{l}\text { Puffing of the body hair } \\
\text { Calm locomotion } \\
\text { Inactive rest }\end{array}$ \\
$\begin{array}{l}\text { Movement between locations with relaxed gait } \\
\text { Stationary behavior with relaxed facial expression and } \\
\text { minimal scanning; tail can be curled } \\
\text { under body, and eyes may be closed }\end{array}$ \\
\hline
\end{tabular}

Behavioral assessments. Elevated levels of E2 are associated with reduced anxiety in women (Maeng and Milad, 2015); and while breast cancer survivors report increased depression and anxiety relative to women with no cancer history (Hansen et al., 2008), the impact of AI use on these symptoms is poorly understood. To investigate whether daily letrozole administration impacts anxiety-like behavior in GDX marmosets, spontaneous behaviors of each marmoset pair were recorded daily for $5 \mathrm{~d}$ for $10 \mathrm{~min}$ alternating between 9:00 A.M. to 10:00 A.M. and 4:00 P.M. to 5:00 P.M. This ensured that behavioral data were collected at least twice during each time period (A.M./P.M.) for each subject. Treatment groups were represented in each pair, which limits time of day as a potential confound for differences in treatment groups on the observed behaviors. Vigilant and anxiety-like behaviors (agitated locomotion, inactive alert, scentmark, piloerection), relaxed locomotion (i.e., calm locomotion), and rest (i.e., inactive rest) of each marmoset were later scored by an observer blind to group membership using ODLog (2.7.2, Macropod software 2012). A behavioral ethogram of these six behaviors is presented in Table 1. The duration (in seconds) of each behavior was averaged for A.M. and P.M. observations of each subject.

Thermal challenge. Both estrogen deprivation following menopause (Sievert, 2013; De Zambotti et al., 2014) and AI use (Kligman and Younus, 2010) are associated with hot flashes. Hot flashes result from thermodysregulation as indicated by rapid fluctuations in heat dissipation responses, including skin conductance, skin blood flow, and temperature (Freedman, 2014). A common method to induce hot flashes in postmenopausal women is to apply heating pads on their abdomen (Freedman, 1989; Sievert et al., 2002). In the present study, a similar procedure was used. A sitting experimenter held the marmoset on her lap with two hands for $20 \mathrm{~min}$. One hand covering the abdomen held a hand warmer that provided the heating source. To prevent overheating, the hand warmer was inserted between two cotton gloves, and had no direct contact with the experimenter's or monkey's skin. For additional protection of the monkey, the hand was covered with a nitrile glove. The hand was kept on the abdomen for a total of $20 \mathrm{~min}$. A second experimenter, sitting $\sim 20 \mathrm{~cm}$ from the animal's face, recorded the facial temperature of the marmoset using a thermal imaging camera (FLIR One for iOS) connected to an iPhone $5 \mathrm{~s}$ (see Fig. 4A). Thermal imaging has been shown to be an effective method to measure hot flashes in women (Jayasena et al., 2015). The experimenter focused the camera on the marmoset's face using the crosshair of the camera as a guide. The camera provided a video of the face along with a measurement of temperature (in ${ }^{\circ} \mathrm{F}$ ) on the crosshair location. The sensitivity of the camera was $0.18^{\circ} \mathrm{F}$. One of every 25 frames was extracted from each video using VLC media player, resulting in $\sim 670$ frames for each animal $(33 / \mathrm{min})$. An experimenter blind to group assignment visually inspected each frame and removed those for which the spot meter was incorrectly placed (located off the face, or on the eye or mouth). The temperature values obtained from each remaining frame $(122 \pm 60)$ were averaged in $1 \mathrm{~min}$ bins for each animal. One marmoset was removed from subsequent analyses, as too many frames were removed, leaving $4 \mathrm{~min}$ unaccounted for during the 20 min challenge. For every minute of the thermal challenge, each marmoset obtained a change score, which was calculated as the percentage change in temperature $\left({ }^{\circ} \mathrm{F}\right)$ from the first min of the challenge (i.e., baseline).

Delayed matching-to-position. Estrogens play an important role in regulating HPC structure and function in both sexes (Frick et al., 2018). Aromatase is expressed in the HPC (Hojo et al., 2004), and AIs have been shown to impact HPC-dependent memory in animals (Tuscher et al., 2016; Bailey et al., 2017) and humans (Collins et al., 2009; Bayer et al., 2015). As a first demonstration of the impact of continuous oral AI use in nonhuman primates, we chose a task that is known to involve this structure. The DMP task requires monkeys to discriminate between two locations and displace a token that previously concealed a food reward (see Fig. $3 A$ ). At the beginning of each session, monkeys entered a transport box affixed to their home cage. The front of the box was made of wire mesh, allowing the monkeys to pass their hands and arms to manipulate objects presented in a modified version of the Wisconsin General Testing Apparatus $(43.2 \times 42.3 \times 44.5 \mathrm{~cm})$. The test tray for the DMP task contained 4 food wells ( $2.5 \mathrm{~cm}$ in diameter). All four positions were used, and the location of the sample token during each trial was pseudorandomized. Subjects were trained until reliable performance was achieved ( 8 of 12 trials over two consecutive days). Only 9 marmosets (vehicle: males: $n=3$; females: $n=1$; letrozole: males: $n=3$; females: $n=2$ ) achieved reliable performance following a brief retention delay $(1 \mathrm{~s})$ and so were tested ( 12 trials/d for $5 \mathrm{~d}$ ) during the baseline and treatment phases. The mean accuracy for each phase (baseline/treatment) was the dependent variable.

Euthanasia and tissue retrieval. Each animal was sedated with ketamine $(10 \mathrm{mg} / \mathrm{kg}$, i.m.), then given an intracardial overdose of pentobarbital (50 $\mathrm{mg} / \mathrm{kg}$ ). The brain was removed, and the hemispheres were separated. The right hemisphere was immediately placed on dry ice, then transferred to a $-80^{\circ} \mathrm{C}$ freezer for later analyses. The frontal cortex, hypothalamus, and HPC were dissected from the left hemisphere. The HPC was divided in two along the septotemporal axis. The lateral aspect of the HPC was immediately transferred to ice-cold slicing solution (see below). The remaining samples were placed in centrifuge tubes and stored in a $-80^{\circ} \mathrm{C}$ freezer.

Electrophysiological recordings. Several lines of research demonstrate the importance of estrogens in regulating the physiology of CA1 neurons. E2 has been shown to decrease the threshold needed to induce LTP (Wong and Moss, 1992). Estrogen deprivation via ovariectomy has been shown to reduce the intrinsic excitability (IE) of these neurons (Wu et al., 2011), yet it is currently unclear whether AIs will have similar effects on CA1 physiology. To determine whether E2 synthesis inhibition via letrozole administration induces comparable changes, similar measures of IE were collected in the present study.

Once removed, the HPC was placed in ice-cold slicing solution containing the following (in mM): 248 glycerol, $3 \mathrm{KCl}, 1 \mathrm{MgSO}_{4} 2 \mathrm{CaCl}_{2}, 1$ $\mathrm{KH}_{2} \mathrm{PO}_{4}, 26 \mathrm{NaHCO}_{3}, 10$ glucose, and bubbled with $95 \% \mathrm{O}_{2} / 5 \% \mathrm{CO}_{2}$. Sagittal sections $(300 \mu \mathrm{M})$ through the HPC were prepared using a VT1000 S vibratome (Leica Biosystems). Slices were incubated at $95^{\circ} \mathrm{F}$ for $30 \mathrm{~min}$ in bubbled recording solution containing the following (in $\mathrm{mm}$ ): $124 \mathrm{NaCl}, 3 \mathrm{KCl}, 1 \mathrm{MgSO}_{4} 2 \mathrm{CaCl}_{2}, 1 \mathrm{KH}_{2} \mathrm{PO}_{4}, 26 \mathrm{NaHCO}_{3}, 10$ glucose, after which they were left at room temperature for $30 \mathrm{~min}$ or up to $8 \mathrm{~h}$ before recording. Recording pipettes were pulled from borosilicate glass (4-7 MOhm) using a PC-10 puller (Narishige) and filled with internal solution containing the following (in $\mathrm{mM}$ ): 120 K-gluconate, $20 \mathrm{KCl}, 0.1 \mathrm{CaCl}_{2}, 5 \mathrm{HEPES}, 5 \mathrm{EGTA}, 3 \mathrm{MgATP}, 0.5$ $\mathrm{Na}-\mathrm{GTP}$, and 10 phosphocreatine. Slices were placed in a recording chamber and perfused with bubbled recording solution throughout the experiments.

A Nikon FN-1 microscope with DIC optics was used to identify pyramidal neurons in the CA1 region. Whole-cell recordings were made with an EPC-10 patch-clamp amplifier and Patchmaster software (HEKA). Resting membrane potential (RMP) and spontaneous spiking activity were measured under current-clamp configuration with zero-injected current. To measure excitability, membrane voltage was recorded in response to current injection ( -50 to $90 \mathrm{pA}, 10 \mathrm{pA}$ increments, $500 \mathrm{~ms}$ duration). Recordings were discarded if holding current rose $>100 \mathrm{pA}$ or 

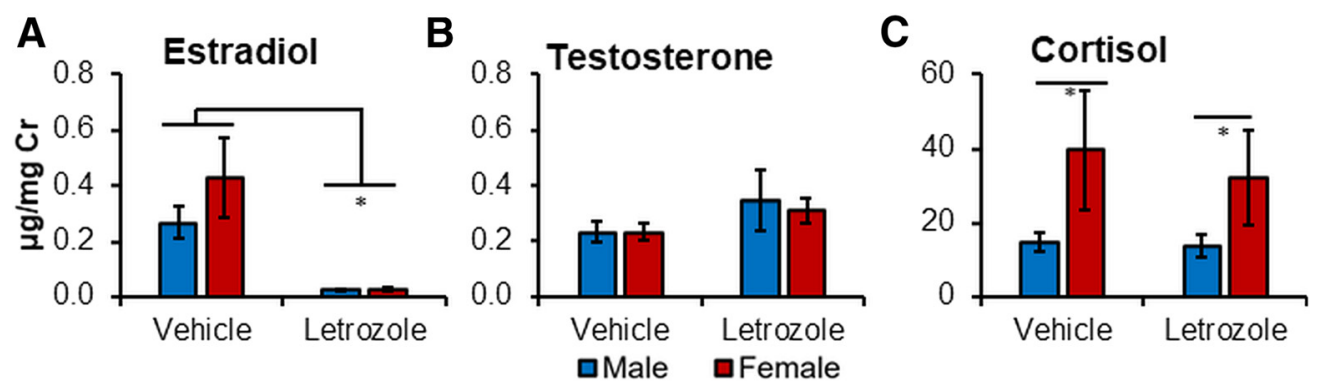

Figure 1. Four weeks of letrozole treatment ( $20 \mu \mathrm{g} / \mathrm{d}$, p.o.) lowers circulating levels of $\mathrm{E} 2$ but has no effect on $\mathrm{T}$ or cortisol. Urinary hormone levels were collected from a mixed-sex sample of marmosets, who received either letrozole (males: $n=4$; females: $n=3$ ) or vehicle (males: $n=4$; females: $n=4$ ). $A$, E2 levels were significantly lower in the letrozole-treated than the control group. ${ }^{*} p<0.001$. Free $T(\boldsymbol{B})$ and cortisol $(\boldsymbol{C})$ levels were not different across treatment groups but were higher in females than males. ${ }^{*} p<0.05$. Mean values obtained in each group are presented in $\mu \mathrm{g} / \mathrm{mg}$ Cr. Error bars indicate SEM.
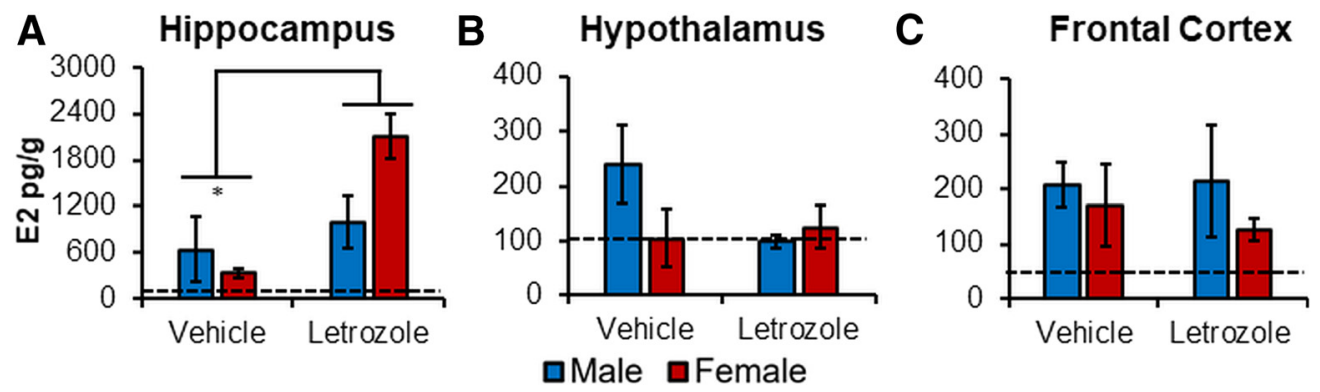

Figure 2. Region-specific increase in E2 levels following 4 weeks of letrozole (20 $\mu \mathrm{g} / \mathrm{d}$, p.o.). Brain regions analyzed were as follows: ( $\boldsymbol{A})$ hippocampus, $(\boldsymbol{B})$ hypothalamus, and (C) frontal cortex. Letrozole (males: $n=4$; females: $n=3$ ) was associated with higher E2 levels in the hippocampus relative to the control group (males: $n=4$; females: $n=4$ ). ${ }^{*} p<0.05$. Remaining regions were unaffected by drug treatment. There was no effect of sex on E2 levels of any region. Mean values obtained in each group are presented in $\mathrm{pg} / \mathrm{g}$. Error bars indicate SEM. Dashed horizontal lines indicate the average background E2 levels obtained by EIA for assay blanks.

if series resistance rose $>30 \mathrm{MOhm}$ (measured in response to $-5 \mathrm{mV}$ test pulses in voltage-clamp mode) over the course of a recording.

Data were analyzed offline using custom scripts written in Igor Pro 6 (Wavemetrics). Visualization of data analyses was performed with custom scripts in MATLAB, and visualization of recording traces was performed in Igor Pro. RMP was calculated as the average subthreshold membrane voltage during spontaneous recordings. Current-voltage characteristics were generated but were not observed to be altered by drug treatment. RMP was derived separately for firing rate vs input (FI) curves and afterhyperpolarization (AHP) analyses. RMP was determined by finding the average of all points spanning the injection of current, and excluding particular points algorithmically determined to be a part of a spike (defined as those at which the trace's smoothed slope crossed a threshold of 1).

AHP amplitude was derived by finding the minimum value during a window between the peak of the action potential and the return to RMP. This minimum was then subtracted from the RMP, and all points outside of plausible thresholds $(-40 \mathrm{mV}$ to $-90 \mathrm{mV}$ ) were excluded from the average. Representative recordings from CA1 pyramidal neurons obtained from one vehicle-treated and one letrozole-treated marmoset are presented in Figure 6. Spontaneous spiking data were collected across the entire recording of $6.5 \mathrm{~s}$ by counting crossings of a $0 \mathrm{mV}$ threshold. Similarly, current-evoked firing frequency was found by finding all crossings of a $0 \mathrm{mV}$ threshold within the $0.5 \mathrm{~s}$ window of current injection.

Brain E2 extraction and assay. Aromatase expression occurs in both the hypothalamus and HPC across several species (Vahaba and RemageHealey, 2015), and so these two regions were selected for analysis of E2 levels. The PFC was chosen as a negative control, as there is currently no evidence that aromatase is expressed in this region. E2 levels were measured in homogenized samples $(200 \mu \mathrm{l}$ in $0.1 \mathrm{M} \mathrm{PB})$ of the HPC, frontal cortex, and hypothalamus using an EIA (Cayman Chemical) following a combined solid- and liquid-phase extraction technique described previously (Chao et al., 2011; Tuscher et al., 2016). Three additional homogenized samples were spiked with E2 with known concentrations $(342.4 \mathrm{pg} / \mathrm{ml}, 856 \mathrm{pg} / \mathrm{ml}$, and $2.14 \mathrm{ng} / \mathrm{ml})$, and another four samples with letrozole $(16,32,64$, and $94 \mathrm{pm})$. The extraction process began with three rounds of ether extraction. Once the organic phase was dried, a methanol $(\mathrm{MeOH})$ and dichloromethane $\left(\mathrm{Ch}_{2} \mathrm{Cl}_{2}\right)$ solution was carefully released down the sides of the tube before reevaporating the samples. Dried samples were resuspended in $0.1 \mathrm{M}$ PB, followed by solid-phase extraction, which consisted of eluting the resuspended samples through high performance extraction disk cartridges lined with $\mathrm{C} 18(3 \mathrm{M})$ under vacuum pressure $(-7$ in/Hg). Hydrophilic and hydrophobic (including E2) compounds were eluted using $\mathrm{ddH}_{2} \mathrm{O}(200 \mu \mathrm{l})$ and $100 \%$ methanol $(2 \times 200 \mu \mathrm{l})$, respectively, before air drying in a water bath at $50^{\circ} \mathrm{C}$. A MeOH/ $\mathrm{Ch}_{2} \mathrm{Cl}_{2}$ solution was once again released down the sides of the tube before one final evaporation. Samples were then resuspended in EIA buffer, and E2 levels in each sample were measured from EIA plates using an Epoch Microplate Spectrophotometer plate reader (Biotek) with a $450 \mathrm{~nm}$ filter and Gen5 software. An additional three tubes of unextracted standards of equivalent concentrations to the spiked samples (342.4 pg/ml, $856 \mathrm{pg} / \mathrm{ml}$, and $2.14 \mathrm{ng} / \mathrm{ml}$ ) were included to determine the effectiveness of the extraction protocol in reducing assay interference. The average recovery rate of the extraction efficiency tubes was $98 \%(\mathrm{SD}=22.85 \%)$, indicating high correlation between expected and obtained values. In addition, the E2 levels obtained in the samples spiked with letrozole showed no evidence of cross reactivity with the ELISA antibody.

Statistical analysis. To maintain blindness to treatment assignment, codes were assigned to both groups to run statistical analyses, and were decoded once all analyses were complete. All statistical analyses were conducted using the SPSS software (IBM), with Type I error rate set at $\alpha=0.05$, and results are expressed as mean \pm standard error of the mean (SEM) in Figures 1-5. Peripheral and central hormone levels (Figs. 1,2) were analyzed using two-way ANOVA with treatment and sex as factors. The same analysis was run on spontaneous 
A

Sample phase

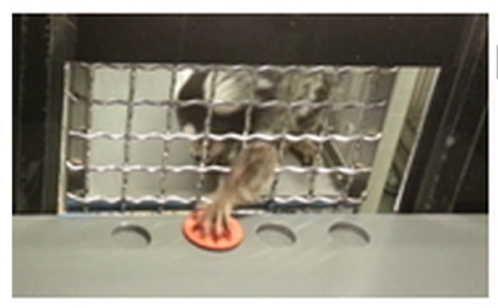

B

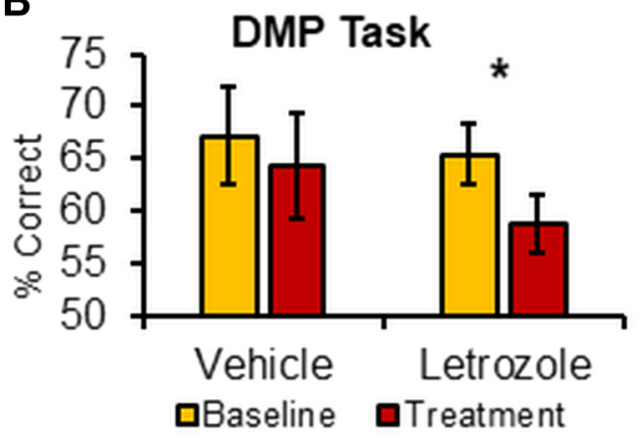

Test phase

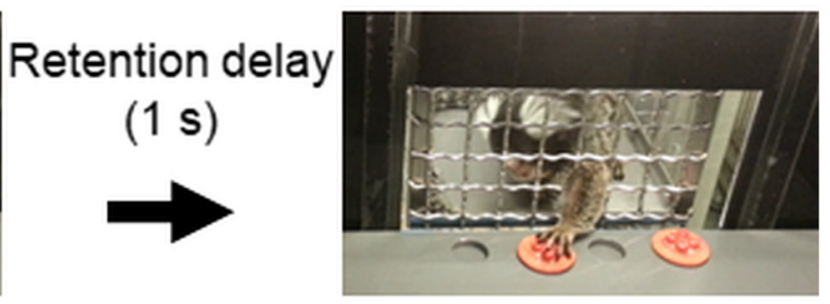

C

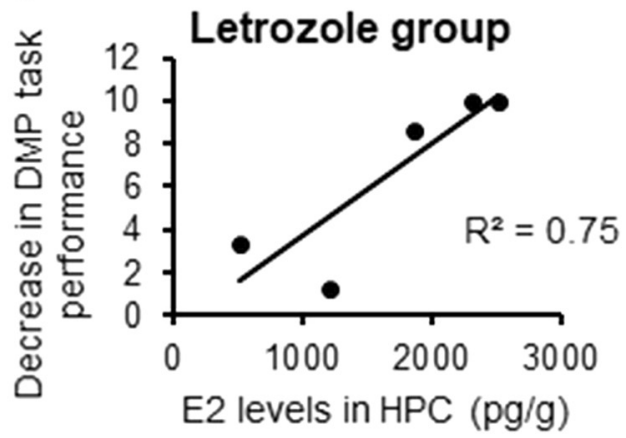

Figure 3. Letrozole ( $20 \mu \mathrm{g} / \mathrm{d}$, p.o.) impairs spatial working memory, possibly by E2 in the hippocampus. $A$, Procedure for a delayed matching-to-sample (DMP) test trial includes the sample phase, when a monkey is presented with a red token placed over 1 of the 4 wells, and is allowed to displace the token to obtain a reward (dehydrated mini marshmallow). The test tray is then concealed from view for $1 \mathrm{~s}$, during which time the reward is replaced and the token is repositioned over the sample location along with an identical token placed over a different well. During the test phase, the monkey must displace the token located in the same position to obtain the reward. Performance was averaged across trials given during a baseline phase, and after 4 weeks of drug treatment. Performance, which was measured as percentage of trials correct, was compared across phases within each experimental group (vehicle: $n=4$; letrozole: $n=5$ ). $\boldsymbol{B}$, Mean accuracy of each group during the baseline and treatment week. Reduced performance was observed in the letrozole group $(n=5)$, whereas performance in the vehicle group $(n=4)$ did not change. ${ }^{*} p<$ 0.05. Error bars indicate SEM. C, A larger reduction in performance is associated with higher E2 levels in the hippocampus within the letrozole group $(r=-0.87, p=0.058)$.

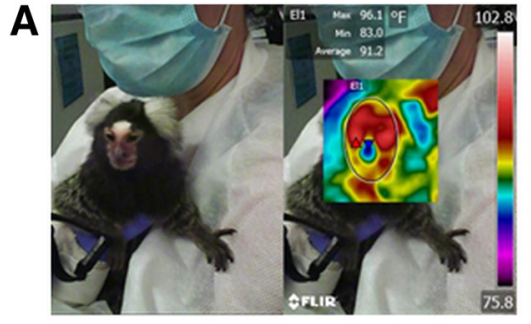

Thermal challenge: +5 min

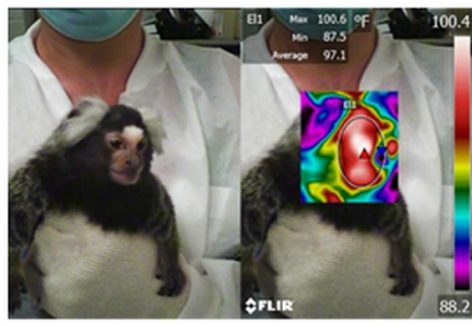

Thermal challenge: $+20 \mathrm{~min}$
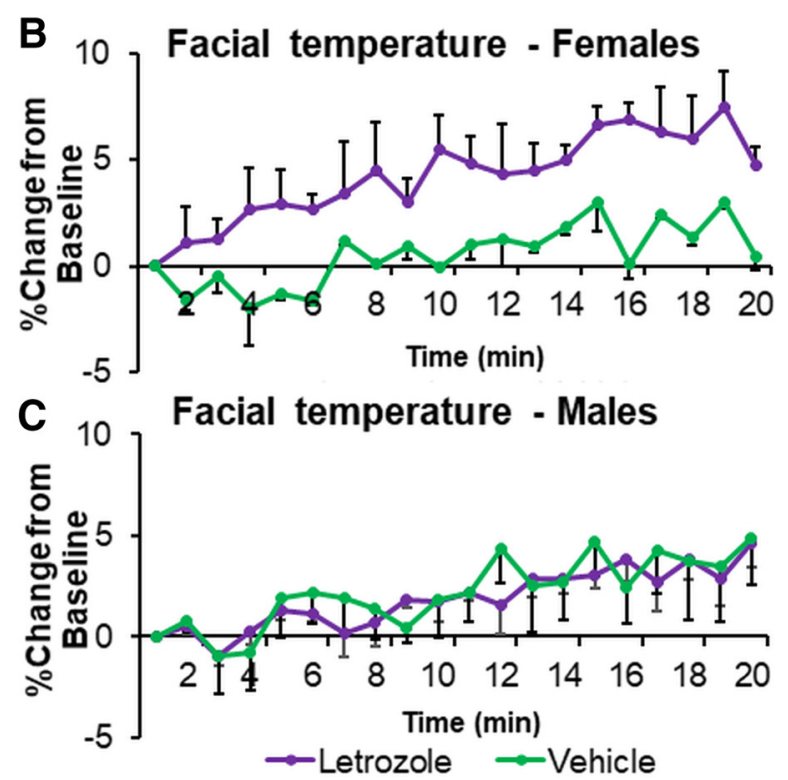

Figure 4. Letrozole ( $20 \mu \mathrm{g} / \mathrm{d}$, p.o.) exerts sex-specific reduction in thermoregulation during thermal challenge. $A$, Facial temperature was measured via thermal camera during a 20 min thermal challenge. Representative images obtained 5 min and 20 min into the challenge are shown, along with the temperature reading. Percentage change in temperature $\left({ }^{\circ} \mathrm{F}\right)$ from the first minutes of the thermal challenge was plotted over time for females ( $\boldsymbol{B}$; vehicle: $n=2$; letrozole: $n=4$ ) and males ( $\boldsymbol{C}$; vehicle: $n=5$, letrozole: $n=4$ ). Letrozole treatment resulted in greater elevation in temperature across time for females only $(p<0.001)$. Error bars indicate SEM.

behaviors (Table 2), with follow-up ANOVAs within each sex. Given the advanced age of some of the marmosets, some were unable to reach criterion performance on the DMP task, and so sex was not included as a factor. Because performance was expected to decrease for the letrozole, but not the vehicle group as treatment progressed, change from baseline to the final treatment was analyzed separately within each group using a paired-samples $t$ test (Fig. 3B). Percentage change in temperature from baseline during the thermal challenge 

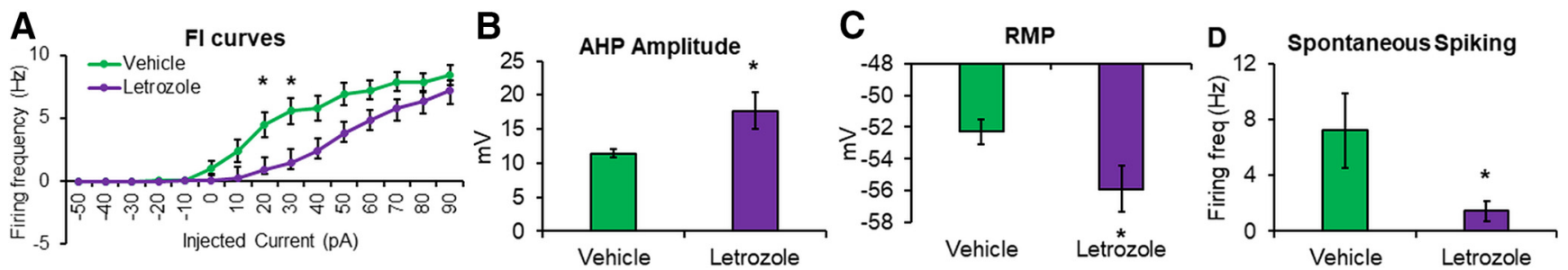

Figure 5. IE of CA1 pyramidal neurons is attenuated by 4 weeks of letrozole treatment $(20 \mu \mathrm{g} / \mathrm{d}, \mathrm{p} .0.) .{ }^{*} p<0.05$ on all 4 measures. This is observed across 4 measures. $A$, Firing frequency (Hz) is attenuated as a function of injected current from letrozole-treated cells $(n=14)$ relative to vehicle $(n=15)$. This shift in excitability was also related to changes in spontaneous activity by letrozole treatment, as indicated by $(\boldsymbol{B})$ greater AHP amplitude (AHP; $\mathrm{mV}),(\boldsymbol{C})$ lower RMP (mV), and (D) lower spontaneous spike rate (Hz). Error bars indicate SEM.

Table 2. Average duration (in seconds) of each behavior during 10 min session recorded during final treatment week ${ }^{a}$

\begin{tabular}{|c|c|c|c|c|}
\hline \multirow[b]{2}{*}{ Behavior } & \multicolumn{2}{|l|}{ AM } & \multicolumn{2}{|l|}{ PM } \\
\hline & Vehicle & Letrozole & Vehicle & Letrozole \\
\hline Agitated locomotion* & $0.86 \pm 0.41$ & $6.16 \pm 2.02$ & $2.57 \pm 0.43$ & $0.58 \pm 0.20$ \\
\hline Inactive alert* & $220.54 \pm 51.89$ & $291.98 \pm 62.58$ & $3261.38 \pm 59.95$ & $271.02 \pm 53.87$ \\
\hline Gouge & $5.28 \pm 3.66$ & $0.21 \pm 0.43$ & $0.58 \pm 0.37$ & $0.79 \pm 0.79$ \\
\hline Scentmark & $0.78 \pm 0.54$ & $0.13 \pm 0.13$ & 0 & 0 \\
\hline Piloerection & 0 & $0.08 \pm 0.08$ & $0.40 \pm 0.40$ & 0 \\
\hline Calm locomotion & $16.88 \pm 4.25$ & $11.11 \pm 3.01$ & $11.16 \pm 2.86$ & $13.88 \pm 4.19$ \\
\hline Inactive rest & $65.06 \pm 45.67$ & $16.37 \pm 10.78$ & $313.18 \pm 6.46$ & $47.06 \pm 16.04$ \\
\hline
\end{tabular}

${ }^{a}$ Values are mean \pm SEM. Letrozole-treated marmosets spent more time in agitated locomotion than those treated with Vehicle in the morning $\left.{ }^{*} p=0.043\right)$. Males treated with letrozole spent more time in inactive alert than Vehicle-treated males in the evening $\left({ }^{*} p=0.044\right)$.

was analyzed using a three-way ANOVA, with treatment and sex as between-subjects factors and time as a within-subjects factor (Fig. $4 B, C)$. Follow-up two-way ANOVAs were conducted within each sex, with time and treatment as factors. Independent-samples $t$ tests were used to analyze treatment effects on passive properties of IE of CA1 neurons (Fig. $5 B-D$ ). To examine the firing frequency at increasing current ( -50 to 90 pA; Fig. $5 A$ ), a two-way ANOVA with follow-up independent-samples $t$ tests were conducted.

In addition to investigating group differences on E2 levels and each outcome measure, selective relations were also examined. Because E2 synthesis inhibition in the HPC has been shown to impair HPCdependent memory, it was expected that HPC-E2 would correlate positively with DMP task performance and excitability of CA1 neurons. It was also predicted that hypothalamic E2 would correlate negatively with the degree of facial temperature change during the thermal challenge, given that thermosensitive neurons responsible for maintaining body temperature are located in the preoptic area (POA) (Rance et al., 2013).

\section{Results}

Letrozole lowers peripheral E2 levels

To confirm that 4 weeks of letrozole decreases peripheral levels of E2 in each sex, comparisons were run on urinary levels of the hormone (Fig. 1A). Additional analyses were run on T (Fig. 1B) and cortisol (Fig. $1 C$ ) to determine whether these hormones are also influenced by the treatment. A main effect of treatment was observed for E2 $\left(F_{(1,12)}=24.69, p=0.0003, \eta^{2}=0.67\right.$; Fig. $\left.1 A\right)$, with lower levels observed in the letrozole-treated group $(0.03 \pm$ $0.004 \mu \mathrm{g} / \mathrm{mg} \mathrm{Cr})$ compared with the vehicle group $(0.33 \pm 0.07$ $\mu \mathrm{g} / \mathrm{mg}$ Cr; Hedge's $\mathrm{g}=-2.17)$. No effect of $\operatorname{sex}\left(F_{(1,12)}=1.57\right.$, $\left.p=0.24, \eta^{2}=0.12\right)$ or interaction $\left(F_{(1,12)}=1.43, p=0.25, \eta^{2}=\right.$ 0.11 ) was observed. Similar levels of T were observed across treatment group and sex, with no significant main effect or interaction $\left(\operatorname{sex}: F_{(1,12)}=1.14, p=0.307, \eta^{2}=0.09\right.$; drug: $F_{(1,12)}=0.22, p=$ $0.645, \eta^{2}=0.02$; interaction: $F_{(1,12)}=1.82, p=0.20, \eta^{2}=0.13$; Fig. $1 B)$. A main effect of sex was observed for cortisol $\left(F_{(1,12)}=\right.$ 5.71, $p=0.034, \eta^{2}=0.32$ ), with higher levels observed in females
$(35.22 \pm 12.85 \mu \mathrm{g} / \mathrm{mg} \mathrm{Cr})$ than males $(14.33 \pm 1.90 \mu \mathrm{g} / \mathrm{mg} \mathrm{Cr}$, Hedge's $g=1.11)$. No effect of treatment $\left(F_{(1,12)}=0.23, p=0.64\right.$, $\eta^{2}=0.02$, Fig. $\left.1 C\right)$ or interaction $\left(F_{(1,12)}=0.13, p=0.73, \eta^{2}=\right.$ 0.01 ) was observed for cortisol.

\section{Letrozole increases HPC-E2 levels}

E2 levels in the HPC, hypothalamus, and frontal cortex were analyzed next. Results revealed a main effect of treatment on E2 levels in the $\operatorname{HPC}\left(F_{(1,10)}=6.33, p=0.031, \eta^{2}=0.39\right.$; Fig. $\left.2 A\right)$, with higher levels in the letrozole-treated $(1471.32 \pm 311.97$ $\mathrm{pg} / \mathrm{g})$ than in the control animals $(522.67 \pm 300.76 \mathrm{pg} / \mathrm{g}$; Hedge's $\mathrm{g}=1.12)$. No effect of $\operatorname{sex}\left(F_{(1,10)}=0.93, p=0.36, \eta^{2}=0.09\right)$ or interaction $\left(F_{(1,10)}=2.86, p=0.12, \eta^{2}=0.22\right)$ was observed. No main effects or interactions were observed for the hypothalamus (sex: $F_{(1,9)}=0.84, p=0.38, \eta^{2}=0.09$; treatment: $F_{(1,9)}=1.00$, $p=0.36, \eta^{2}=0.17$; interaction: $F_{(1,9)}=1.78, p=0.22, \eta^{2}=$ 0.17 ; Fig. $2 B$ ) or frontal cortex (treatment: $F_{(1,11)}=1.13, p=$ $0.307, \eta^{2}=0.09$; sex: $F_{(1,11)}=0.10, p=0.76, \eta^{2}=0.01$; interaction: $F_{(1,11)}=0.21, p=0.66, \eta^{2}=0.02$; Fig. $\left.2 C\right)$.

\section{Letrozole decreases some anxiety-like behaviors}

To determine whether oral letrozole given to marmosets mimics mood changes reported by women taking AIs, spontaneous behaviors were compared across treatment and sex. A significant main effect of treatment was observed for time spent in agitated locomotion in the morning $\left(F_{(1,12)}=5.12, p=0.043\right.$, partial $\eta^{2}=0.30$ ), with longer duration observed in the letrozole group $(6.16 \pm 2.02 \mathrm{~s})$ than the vehicle group $(0.86 \pm 0.41 \mathrm{~s}$; Hedge's $\mathrm{g}=$ 1.28). An interaction was observed for time spent in inactive alert in the afternoon $\left(F_{(1,12)}=10.90, p=0.006\right.$, partial $\left.\eta^{2}=0.48\right)$. Follow-up comparisons revealed more time spent in inactive alert for males treated with letrozole than controls $\left(F_{(1,7)}=6.03\right.$, $p=0.044$, partial $\eta^{2}=0.46$; letrozole $=375.22 \pm 56.51 \mathrm{~s}$; vehicle $=180.92 \pm 54.36$, Hedge's $g=1.65)$, whereas a marginally significant effect was found in females $\left(F_{(1,5)}=4.81, p=0.08\right.$, partial $\eta^{2}=0.49$; letrozole $=166.82 \pm 55.79 \mathrm{~s}$; vehicle $=$ $395.48 \pm 96.46$, Hedge's $g=-1.68$ ). No other comparisons were significant. Table 2 presents the mean duration of each behavior for the vehicle and letrozole-treated group in the morning and afternoon.

\section{Letrozole impairs HPC-dependent cognition}

A statistically significant decrease in performance was observed in the letrozole-treated group $\left(t_{(4)}=3.66, p=0.022\right.$, Hedge's $g=$ 1.16; Performance change: males $=4.42 \pm 2.18 \%$; females $=$ $10 \pm 0 \%)$, whereas no change was observed in the vehicle-treated group $\left(t_{(3)}=0.40, p=0.71\right.$, Hedge's $g=0.34$, Fig. $3 B$; males $=$ $-0.26 \pm 15.68 \%$; females $=12.27 \pm 0 \%$, Fig. $2 B$ ). 
A

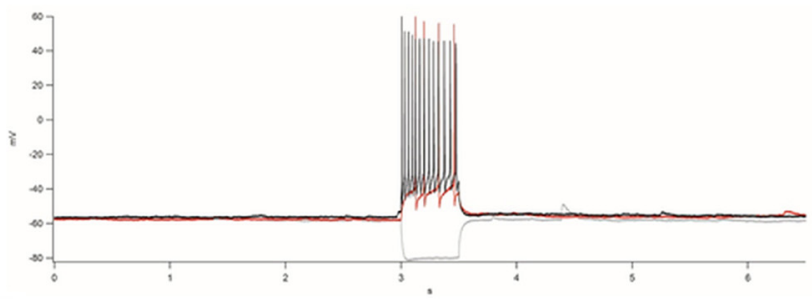

B

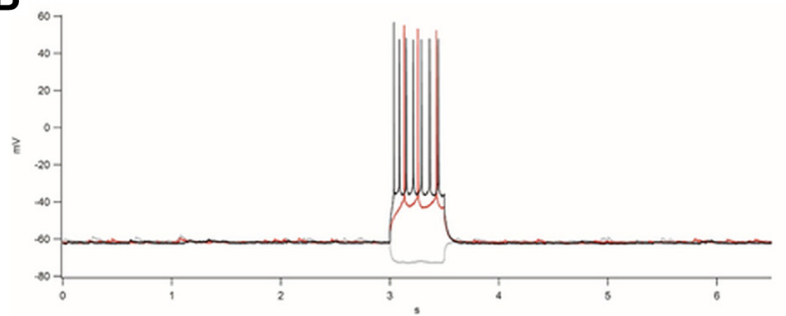

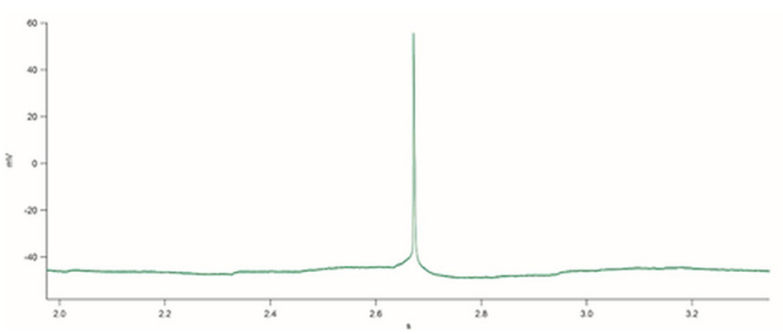

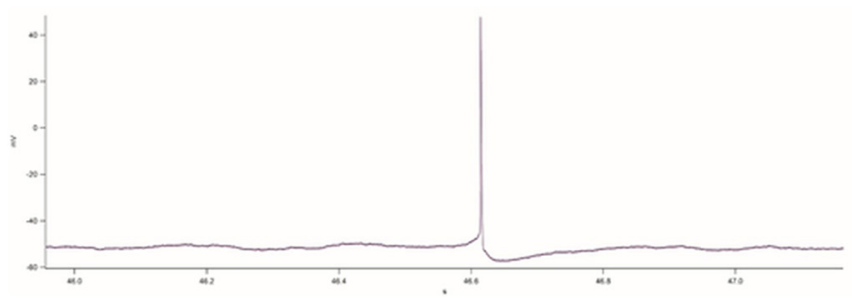

Figure 6. Representative recordings from CA1 pyramidal cells from animals following vehicle treatment ( $\boldsymbol{A}$ ) and letrozole treatment (B). Left, Voltage traces during $500 \mathrm{~ms}$ current steps. Gray represents $-50 \mathrm{pA}$. Red represents rheobase. Black represents twice rheobase. Right, Single spontaneous action potentials showing differences in AHP amplitude.

\section{Letrozole increases facial temperature during thermal challenge in females}

Letrozole-induced change in facial temperature during a thermal challenge was investigated to determine whether marmosets in the letrozole group experience thermodysregulation, mimicking hot flashes reported by women taking AIs. A main effect of sex $\left(F_{(1,4)}=8.81, p=0.041, \eta^{2}=0.69\right)$ and time $\left(F_{(19,76)}=21.69\right.$, $p=0.000$, partial $\left.\eta^{2}=0.84\right)$, a two-way interaction between treatment and sex $\left(F_{(1,4)}=15.26, p=0.017, \eta^{2}=0.79\right)$, treatment and time $\left(F_{(19,76)}=2.62, p=0.002\right.$, partial $\left.\eta^{2}=0.39\right)$, and sex and time $\left(F_{(19,76)}=2.64, p=0.001\right.$, partial $\left.\eta^{2}=0.40\right)$, and a three-way interaction between sex, treatment, and time $\left(F_{(19,76)}=\right.$ $2.72, p=0.001$, partial $\eta^{2}=0.40$ ). A follow-up two-way ANOVA conducted within each sex revealed a main effect of treatment $\left(F_{(1,3)}=17.10, p=0.026, \eta^{2}=0.85\right)$, time $\left(F_{(19,57)}=15.09, p=\right.$ 0.000 , partial $\left.\eta^{2}=0.83\right)$, and an interaction between treatment and time $\left(F_{(19,57)}=3.37, p=0.000\right.$, partial $\left.\eta^{2}=0.53\right)$ among females (Fig. $4 B$ ), with greater change in facial temperature in the letrozole group (vehicle $=0.54 \%$ change in ${ }^{\circ} \mathrm{F} \pm 0.05$ letrozole $=$ $4.45 \%$ change in ${ }^{\circ} \mathrm{F} \pm 1.46$; Hedge's $\left.g=1.55\right)$. A main effect of time was observed in males $\left(F_{(19,19)}=6.96, p=0.000\right.$, partial $\eta^{2}=0.87$ ), but all other effects were not significant (treatment: $F_{(1,1)}=2.80, p=0.343, \eta^{2}=0.74$; interaction: $F_{(19,19)}=1.51$, $p=0.188$, partial $\eta^{2}=0.60$; Fig. $4 C$ ). Temperature change was similar across the two treatment groups in the males (vehicle = $2.20 \%$ change in ${ }^{\circ} \mathrm{F} \pm 1.75$ letrozole $=1.94 \%$ change in ${ }^{\circ} \mathrm{F} \pm 0.48$; Hedge's g $=-0.09$ ).

\section{Letrozole reduces IE of CA1 neurons}

To observe whether oral letrozole mimics changes in HPC activity known to occur following ovarian hormone deprivation, intrinsic activity of CA1 neurons was compared across treatment groups. FI curves were compared and revealed a significant interaction between treatment and injected current $\left(F_{(4,100)}=2.95\right.$, $p=0.024, \eta^{2}=0.11$, with reduced firing frequency in letrozoletreated cells following currents of $20 \mathrm{pA}\left(t_{(27)}=-2.69, p=0.012\right.$, letrozole $=1.47 \pm 0.54 \mathrm{~Hz}$, vehicle $=4.46 \pm 1.00 \mathrm{~Hz}$, Hedge's $\mathrm{g}=-1.00)$ and $30 \mathrm{pA}\left(t_{(27)}=-2.25, p=0.013\right.$, letrozole $=$ $2.43 \pm 0.62 \mathrm{~Hz}$, vehicle $=5.57 \pm 1.03 \mathrm{~Hz}$, Hedge's $\mathrm{g}=-0.98$;
Fig. 6A). Significant treatment effects were observed on passive measures, with CA1 neurons from the letrozole-treated group demonstrating higher AHP amplitude $\left(t_{(22)}=2.25, p=0.035\right.$, Hedge's $g=0.92$, Fig. $6 B$; letrozole $=0.02 \pm 0.002 \mathrm{~Hz}$, vehicle $=$ $0.01 \pm 0.001 \mathrm{~Hz})$, lower resting membrane potential $\left(t_{(22)}=\right.$ $-2.18, p=0.041$, Hedge's $g=0.89$, Fig. $6 C$; letrozole $=-0.06 \pm$ $0.002 \mathrm{mV}$, vehicle $=-0.05 \pm 0.001 \mathrm{mV})$, and lower spontaneous spiking $\left(t_{(22)}=-2.10, p=0.048\right.$, Hedge's $g=0.86$, Fig. $6 D$; letrozole $=1.43 \pm 0.71 \mathrm{mV}$, vehicle $=1.67 \pm 0.65 \mathrm{mV}$ ) relative to neurons from the vehicle group.

\section{Correlations between study measures}

The relation between E2 levels (peripheral and central) was analyzed for all primary outcome measures. Among the letrozoletreated marmosets, hypothalamic E2 was related to facial temperature change at 4 of the 20 time points $\left(r_{(4)}=0.94-0.98\right.$, $p<0.006$, Bonferroni-corrected), whereas no associations were observed for control animals. Peripheral levels of E2 did not correlate with facial temperature change in either treatment group.

Peripheral E2 levels were not associated with performance on the DMP $\left(r_{(7)}=0.35, p=0.360\right)$ or measures of extrinsic activity of CA1 neurons $\left(r_{(6)}=0.44-0.59, p=0.213-0.381\right)$. A large, nonsignificant negative correlation was found between HPC-E2 levels and the drop in DMP performance in the letrozole group $\left(r_{(3)}=-0.87, p=0.058\right.$; Fig. $\left.3 B\right)$. No such correlation was observed in the vehicle-treated group $\left(r_{(2)}=0.38, p=0.623\right)$. The relation between CA1 activity (AHP, RMP, and spontaneous spiking) and neuroestradiol was also not significant $\left(r_{(6)}=0.08-\right.$ $0.86, p=0.27-.89$ ).

\section{Discussion}

Four weeks of an oral AI (letrozole; $20 \mu \mathrm{g} / \mathrm{d}$ ) has adverse effects on multiple behavioral, neuronal, and physiological outcomes in GDX marmosets $>5$ years old. Reduced performance on the DMP task from baseline to the final treatment week was observed in the letrozole-treated marmosets, whereas no change was observed in controls (Fig. 2B), suggesting that letrozole reduces spatial working memory ability. This is consistent with previous studies demonstrating impaired 
memory following aromatase inhibition in the HPC in rodents (Tuscher et al., 2016; but see Taylor et al., 2017), songbirds (Bailey et al., 2017), and humans (Collins et al., 2009; Bayer et al., 2015; but see Lee et al., 2016).

Letrozole also reduced the IE of pyramidal neurons in the CA1 on multiple measures in both sexes. Relative to controls, neurons from the letrozole-treated animals demonstrated reduced responsiveness to injected current, and lower spontaneous activity. These properties together reflect a compromised state of IE because they govern how effective synaptic inputs translate to action potentials. The reduced IE of CA1 neurons is consistent with results reported in rats following short- (2 months) or long-term (5 months) ovarian hormone deprivation (via OVX) (Wu et al., 2011). In that study, long-term OVX resulted in reduced neuronal responsiveness to injected current, and steeper AHP slope. Together, these results suggest that 4 weeks of letrozole treatment mimics the detrimental effects of long-term ovarian hormone deprivation on IE and spontaneous activity. While E2 is known to enhance excitatory synaptic transmission in the HPC (Wong and Moss, 1992; Smejkalova and Woolley, 2010; Wu et al., 2011), peripheral and HPC-E2 levels were not correlated with IE, suggesting that letrozole impacts HPC physiology via other mechanisms. One advantage of the present study over previous research is that neurons from both males and females were included. Because the data are consistent across both sexes, these results indicate that letrozole has detrimental effects on the IE of CA1 neurons regardless of sex.

The increase in facial temperature in response to a thermal challenge was higher in letrozole-treated monkeys than controls, but in female marmosets only. This indicates that letrozoletreated females were less able to regulate their body temperature than vehicle-treated females. E2 is known to decrease core body temperature in women (Tankersley et al., 1992; Brooks et al., 1997), female rodents (e.g., Dacks and Rance, 2010), and female marmosets (Gervais et al., 2016), and AI treatment triggers hot flashes in breast cancer patients (Kligman and Younus, 2010). Both endogenous E2 levels (Baker et al., 2015) and estrogen therapy (Freedman and Blacker, 2002) are associated with fewer hot flashes. Circulating E2 levels were not associated with change in facial temperature in either group in the present study, but hypothalamic E2 levels correlated positively with facial temperature change within the letrozole-treated marmosets. As the hypothalamus, and in particular the POA, contains thermosensitive neurons that play a role in thermoregulation (for review, see Rance et al., 2013), it is possible that aromatase inhibition impairs thermoregulation via mechanisms that involve E2 in this structure. No group differences in hypothalamic E2 levels were observed, but the analyzed tissue included all subregions of the hypothalamus, and so any effect on the POA might have been masked. While the results of the present study suggest that aromatase inhibition compromises thermoregulation in a sex-specific manner, other known sex differences can also explain the observed findings, including differences in the POA (Ayoub et al., 1983), body physiology, anthropometric characteristics, and body composition (for review, see Kaciuba-Uscilko and Gruza, 2001). In addition, we cannot rule out that the observed sex difference resulted from an interaction between the potential stress associated with the thermal challenge and sex. Future studies are needed to better understand sex differences in thermoregulation and the contribution of neuroestradiol in regulating thermosensitive neurons.
Some vigilant behaviors were increased by letrozole treatment, although time of day appears to have influenced the pattern of results. In the morning, letrozole-treated marmosets spent more time in agitated locomotion, a sensitive marker for anxiety (Bowell, 2010). Consistent with this, males taking letrozole spent more time in inactive alert in the afternoon relative to control males, indicative of heightened vigilance, a behavioral marker similar to trait anxiety in humans (Shiba et al., 2014). Letrozole had no effect on this behavior in females. Thus, greater inactive alert and agitated locomotion likely reflect greater anxiety. There are inconsistencies with regards to the effects of aromatase inhibition on anxiety in rodents, with one study showing impaired fear extinction (i.e., greater fear maintenance) in male rats following acute inhibition (Graham and Milad, 2014) and others reporting no effect of sustained inhibition on open field activity in OVX/castrated rats (Kokras et al., 2018), and no difference between ArKO and WT mice on the open field and elevated plus maze (Dalla et al., 2005). While the results of the current study suggest that daily oral AI can have anxiogenic properties, more research in this area is needed before firm conclusions can be drawn.

As predicted, peripheral levels of $\mathrm{E} 2$ were reduced by letrozole treatment, but a region-specific effect was observed in the brain, with higher E2 levels detected in the HPC of letrozoletreated tissue, and no effect in the PFC and hypothalamus. Letrozole clearly crosses the blood-brain barrier as demonstrated in rats (Dave et al., 2013), with exposure to the brain being dose-dependent. It is possible that the letrozole dose was too low to effectively suppress aromatase activity in the brain, whereas it did so at the periphery. Indeed, our data are consistent with a "compensation" hypothesis, suggesting that elevated HPC-E2 levels result from increased aromatase expression and/or activity in response to lower peripheral level of E2. In support of this interpretation, increased aromatase expression is observed following OVX in rhesus monkeys (Higaki et al., 2012). Further, data in zebra finches show that continuous administration of oral AI leads to increased expression of aromatase protein, whereas elevated peripheral levels of E2 downregulate aromatase in the HPC, but not other brain areas, including the POA (Saldanha et al., 2000). Such region-specific patterns of aromatase expression are consistent with our data, which show differential responses of the HPC versus hypothalamus and frontal cortex. Studies using direct administration of AIs within the HPC show reduced E2 synthesis in the HPC, both in female mice (Tuscher et al., 2016) and male songbirds (Bailey et al., 2017). Similarly, in vitro studies of HPC neurons demonstrate reduced E2 synthesis following letrozole administration through a mechanism of phosphorylation that inactivates aromatase without decreasing aromatase expression (Fester et al., 2016). Similarly, E2 levels may be altered centrally due to alterations in catabolism or inactivation of estrogens by enzymes, such as suppression of 2-hydroxylase (Osawa et al., 1993; Zhu and Conney, 1998). The mechanisms underlying differential effects of letrozole according to the mode (oral or central) of administration remain to be determined.

As mentioned above, the dose of administration is important for the extent of brain exposure. There is also evidence that the duration of administration may be crucial to understanding letrozole mechanisms. ER-responsive tumors can often escape inhibition with prolonged letrozole treatment $\mathrm{Ma}$ et al., 2015). There is also evidence for differential effects of letrozole on depressive-like behavior in female rats depending 
on whether it is administered acutely ( 3 injections in $24 \mathrm{~h}$ ) or continuously (7 d) (Kokras et al., 2018). Because AIs are administered both orally, at low dose and continuously in women, one prediction from our study is that they induce elevated HPC E2 levels, an intriguing possibility that will require empirical validation.

The present results suggest that higher HPC-E2 levels are related to greater performance deficits on the DMP task in the letrozole group, which is in contradiction with studies using intracerebral administration of AIs, finding impaired spatial learning and memory (Tuscher et al., 2016; Bailey et al., 2017) following reduced E2 levels in the HPC. Although no correlation was observed, elevated HPC-E2 levels might also lead to reduced IE of CA1 neurons. As predicted by the compensation hypothesis, prolonged use of AIs may reduce the functionality of the HPC by increasing aromatase expression/activity, resulting in elevated HPC-E2 levels, impaired spatial memory, and compromised IE of CA1 neurons. Prolonged use of letrozole might also lead to the observed findings through escaped inhibition. Future studies are needed to address these important questions.

This was the first study using a nonhuman primate to examine the effects of letrozole on brain and behavior. We used a regimen that mimics AI use in humans, examined a large number of behavioral measures, spanning cognition to anxiety to thermoregulation and analyzed sex differences. At the brain level, we measured both E2 content in several brain regions and HPC neuron physiology. Such a comprehensive approach in an animal model phylogenetically close to humans is unique and a great strength of the study. There were also limitations associated with the use of nonhuman primates. The relatively small sample, the broad age range, and the use of a single cognitive task limit the conclusions that can be drawn from our results.

Nevertheless, we demonstrated that 4 weeks of oral administration of the AI letrozole at a dose comparable with what is used by women effectively reduces peripheral levels of E2 but leads to a compensatory increase in E2 levels in the HPC. Thermoregulation, HPC neural activity, and spatial working memory were all compromised by treatment. These results in a nonhuman primate corroborate many of the symptoms reported by women taking AIs (Bender et al., 2007; Rand et al., 2011) and reveal detrimental effects of these treatments on the brain, in part through elevated HPC-E2 levels. Future studies are needed to elucidate the precise mechanisms by which AIs compromise the CNS.

\section{References}

Ayoub DM, Greenough WT, Juraska JM (1983) Sex differences in dendritic structure in the preoptic area of the juvenile macaque monkey brain. Science 219:197-198. CrossRef Medline

Azcoitia I, Yague JG, Garcia-Segura LM (2011) Estradiol synthesis within the human brain. Neuroscience 191:139-147. CrossRef Medline

Bailey DJ, Makeyeva YV, Paitel ER, Pedersen AL, Hon AT, Gunderson JA, Saldanha CJ (2017) Hippocampal aromatization modulates spatial memory and characteristics of the synaptic membrane in the male zebra finch. Endocrinology 158:852-859. CrossRef Medline

Bajetta E, Zilembo N, Dowsett M, Guillevin L, Di Leo A, Celio L, Martinetti A, Marchianò A, Pozzi P, Stani S, Bichisao E (1999) Double-blind, randomised, multicentre endocrine trial comparing two letrozole doses, in postmenopausal breast cancer patients. Eur J Cancer 35:208-213. CrossRef Medline

Baker FC, Willoughby AR, Sassoon SA, Colrain IM, de Zambotti M (2015) Insomnia in women approaching menopause: Beyond perception. Psychoneuroendocrinol 60: 96-104. CrossRef Medline

Barnett DK, Bunnell TM, Millar RP, Abbott DH (2006) Gonadotropin- releasing hormone II stimulates female sexual behavior in marmoset monkeys. Endocrinology 147:615-623. CrossRef Medline

Barros M, Maior RS, Huston JP, Tomaz C (2008) Predatory stress as an experimental strategy to measure fear and anxiety-related behaviors in non-human primates. Rev Neurosci 19:157-169. Medline

Bayer J, Rune G, Schultz H, Tobia MJ, Mebes I, Katzler O, Sommer T (2015) The effect of estrogen synthesis inhibition on hippocampal memory. Psychoneuroendocrinology 56:213-225. CrossRef Medline

Bender CM, Sereika SM, Brufsky AM, Ryan CM, Vogel VG, Rastogi P, Cohen SM, Casillo FE, Berga SL (2007) Memory impairments with adjuvant anastrozole versus tamoxifen in women with early-stage breast cancer. Menopause 14:995-998. CrossRef Medline

Blaustein JD (2017) Treatments for breast cancer that affect cognitive function in postmenopausal women. Policy Insights Behav Brain Sci 4: 170-177. CrossRef

Bowell VA (2010) Improving the welfare of laboratory-housed primates through the use of positive reinforcement training: practicalities of implementation. Scotland:University of Stirling. Available at http://hdl.handle.net/1893/3442.

Brooks EM, Morgan AL, Pierzga JM, Wladkowski SL, O'Gorman JT, Derr JA, Kenney WL (1997) Chronic hormone replacement therapy alters thermoregulatory and vasomotor function in postmenopausal women. J Appl Physiol 83:477-484. CrossRef Medline

Burstein HJ, Temin S, Anderson H, Buchholz TA, Davidson NE, Gelmon KE, Giordano SH, Hudis CA, Rowden D, Solky AJ, Stearns V, Winer EP, Griggs JJ (2014) Adjuvant endocrine therapy for women with hormone receptor-positive breast cancer: American Society of Clinical Oncology Clinical Practice Guideline Focused Update. J Clin Oncol 32:2255-2269. CrossRef Medline

Chao A, Schlinger BA, Remage-Healey L (2011) Combined liquid and solidphase extraction improves quantification of brain estrogen content. Front Neuroanat 5:57. CrossRef Medline

Chaplin TA, Yu HH, Soares JG, Gattass R, Rosa MG (2013) A conserved pattern of differential expansion of cortical areas in simian primates. J Neurosci 33:15120-15125. CrossRef Medline

Cherrier MM, Matsumoto AM, Amory JK, Ahmed S, Bremner W, Peskind ER, Raskind MA, Johnson M, Craft S (2005) The role of aromatization in testosterone supplementation. Neurology 64:290-296. CrossRef Medline

Chumsri S, Yu S, Schech A, Sabnis G, Brodie A (2016) Aromatase inhibitors for breast cancer prevention. In: Trends in breast cancer prevention (Russo J, ed) pp 103-111. New York: Springer.

Collins B, Mackenzie J, Stewart A, Bielajew C, Verma S (2009) Cognitive effects of hormonal therapy in early stage breast cancer patients: a prospective study, Psychooncology 18:811-821. CrossRef

Cornil CA (2017) On the role of brain aromatase in females: why are estrogens produced locally when they are available systemically? J Comp Physiol 204:31-49. CrossRef Medline

Dacks PA, Rance NE (2010) Effects of estradiol on the thermoneutral zone and core temperature in ovariectomized rats. Endocrinology 151:11871193. CrossRef Medline

Dalla C, Antoniou K, Papadopoulou-Daifoti Z, Balthazart J, Bakker J (2005) Male aromatase-knockout mice exhibit normal levels of activity, anxiety, and "depressive-like" symptomatology. Behav Brain Res 163:186-193. CrossRef Medline

Dave N, Gudelsky GA, Desai PB (2013) The pharmacokinetics of letrozole in brain and brain tumor in rats with orthotopically implanted C6 glioma, assessed using intracerebral microdialysis. Cancer Chemother Pharmacol 72:349-357. CrossRef Medline

De Zambotti M, Colrain IM, Javitz HS, Baker FC (2014) Magnitude of the impact of hot flashes on sleep in perimenopausal women. Fert Steril 102: 1708-1715.e1. CrossRef Medline

Desai K, Mao JJ, Su I, Demichele A, Li Q, Xie SX, Gehrman PR (2013) Prevalence and risk factors for insomnia among breast cancer patients on aromatase inhibitors. Support Care Cancer 21:43-51. CrossRef Medline

Dias JP, Melvin D, Shardell M, Ferrucci L, Chia CW, Gharib M, Egan JM, Basaria S (2016) Effects of transdermal testosterone gel or aromatase inhibitor on prostate volume in older men. J Clin Endocrinol Metab 101:1865-1871. CrossRef Medline

Fentiman IS (2018) The endocrinology of male breast cancer. Endocr Relat Cancer 25:R365-R373. CrossRef Medline

Fester L, Brandt N, Windhorst S, Pröls F, Bläute C, Rune GM (2016) Control 
of aromatase in hippocampal neurons. J Ster Biochem Mol Biol 160: 9-14. CrossRef

Freedman RR (1989) Laboratory and ambulatory monitoring of menopausal hot flashes. Psychophysiology 26:573-579. CrossRef Medline

Freedman RR (2014) Postmenopausal physiological changes. Curr Top Behav Neurosci 21:245-256. CrossRef Medline

Freedman RR, Blacker CM (2002) Estrogen raises the sweating threshold in postmenopausal women with hot flashes. Fertil Steril 77:487-490. CrossRef Medline

Frick KM, Kim J, Koss WA (2018) Estradiol and hippocampal memory in female and male rodents. Curr Opin Behav Sci 23:65-74. CrossRef Medline

Galvão-Coelho NL, Silva HP, Leão Ade C, de Sousa MB (2008) Common marmosets (Callithrix jacchus) as a potential animal model for studying psychological disorders associated with high and low responsiveness of the hypothalamic-pituitary-adrenal axis. Rev Neurosci 19:187-201. Medline

Ganz PA, Petersen L, Bower JE, Crespi CM (2016) Impact of adjuvant endocrine therapy on quality of life and symptoms: observational data over 12 months from the mind-body study. J Clin Oncol 34:816-824. CrossRef Medline

Gervais NJ, Viechweg SS, Mong JA, Lacreuse A (2016) The middle-aged ovariectomized marmoset (Callithrix jacchus) as a model of menopausal symptoms: preliminary evidence. Neuroscience 337:1-8. CrossRef Medline

Graham BM, Milad MR (2014) Inhibition of estradiol synthesis impairs fear extinction in male rats. Learn Mem 21:347-350. CrossRef Medline

Hansen J, Feuerstein M, Calvio L, Olsen C (2008) Breast cancer survivors at work. J Occup Environ Res 50:777-784. CrossRef Medline

Higaki S, Takumi K, Itoh M, Watanabe G, Taya K, Shimizu K, Hayashi M, Oishi T (2012) Response of ER $\beta$ and aromatase expression in the monkey hippocampal formation to ovariectomy and menopause. Neurosci Res 72:148-154. CrossRef Medline

Hoffmann K, Coolen A, Schlumbohm C, Meerlo P, Fuchs E (2012) Remote long-term registrations of sleep-wake rhythms, core body temperature and activity in marmoset monkeys. Behav Brain Res 235:113-123. CrossRef Medline

Hojo Y, Hattori TA, Enami T, Furukawa A, Suzuki K, Ishii HT, Mukai H, Morrison JH, Janssen WG, Kominami S, Harada N, Kimoto T, Kawato S (2004) Adult male rat hippocampus synthesizes estradiol from pregnenolone by cytochromes P45017 $\alpha$ and P450 aromatase localized in neurons. Proc Natl Acad Sci U S A 101:865-870. CrossRef Medline

Jayasena CN, Comninos AN, Stefanopoulou E, Buckley A, Narayanaswamy S, Izzi-Engbeaya C, Abbara A, Ratnasabapathy R, Mogford J, Ng N, Sarang Z, Ghatei MA, Bloom SR, Hunter MS, Dhillo WS (2015) Neurokinin B administration induces hot flushes in women. Sci Rep 5:8466. CrossRef Medline

Kaciuba-Uscilko H, Grucza R (2001) Gender differences in thermoregulation. Curr Opin Clin Nutr Metab Care 4:533-536. CrossRef Medline

Kligman L, Younus J (2010) Management of hot flashes in women with breast cancer. Curr Oncol 17:81-86. CrossRef Medline

Kokras N, Pastromas N, Papasava D, de Bournonville C, Cornil CA, Dalla C (2018) Sex differences in behavioral and neurochemical effects of gonadectomy and aromatase inhibition in rats. Psychoneuroendocrinology 87 : 93-107. CrossRef Medline

Kretz O, Fester L, Wehrenberg U, Zhou L, Brauckmann S, Zhao S, PrangeKiel J, Naumann T, Jarry H, Frotscher M, Rune GM (2004) Hippocampal synapses depend on hippocampal estrogen synthesis. J Neurosci 24: 5913-5921. CrossRef Medline

Lacreuse A, Chang J, Metevier CM, LaClair M, Meyer JS, Ferris CM (2014) Oestradiol modulation of cognition in adult female marmosets. J Neuroendorinol 26: 296-309. CrossRef Medline

Lee PE, Tierney MC, Wu W, Pritchard KI, Rochon PA (2016) Endocrine treatment-associated cognitive impairments in breast cancer survivors: evidence from published studies. Breast Cancer Res Treat 158:407-420. CrossRef Medline

Ma CX, Reinert T, Chmielewska I, Ellis MJ (2015) Mechanisms of aromatase inhibitor resistance. Nat Rev Cancer 15:261-275. CrossRef Medline

Maeng LY, Milad MR (2015) Sex differences in anxiety disorders: interactions between fear, stress, and gonadal hormones. Horm Behav 76:106117. CrossRef Medline

Martin S, Jones M, Simpson E, van den Buuse M (2003) Impaired spatial reference memory in aromatase-deficient (ArKO) mice. Neuroreport 14: 1979-1982. CrossRef Medline

Naftolin F, Ryan KJ, Petro Z (1972) Aromatization of androstenedione by the anterior hypothalamus of adult male and female rats. Endocrinology 90:295-298. CrossRef Medline

Osawa Y, Higashiyama T, Shimizu Y, Yarborough C (1993) Multiple functions of aromatase and the active site structure: aromatase is the placental estrogen 2-hydroxylase. Biochem Mol Biol 44:469-480. Medline

Rance NE, Dacks PA, Mittelman-Smith MA, Romanovsky AA, KrajewskiHall SJ (2013) Modulation of body temperature and LH secretion by hypothalamic KNDy (kisspeptin, neurokinin B and dynorphin) neurons: a novel hypothesis on the mechanism of hot flushes. Front Neuroendocrinol 34:211-227. CrossRef Medline

Rand KL, Otte JL, Flockhart D, Hayes D, Storniolo AM, Stearns V, Henry NL, Nguyen A, Lemler S, Hayden J, Jeter S, Carpenter JS (2011) Modeling hot flushes and quality of life in breast cancer survivors. Climacteric 14: 171-180. CrossRef Medline

Roselli CE (2013) The distribution and regulation of aromatase in the mammalian brain: from mice to monkeys. In: Brain aromatase, estrogens and behavior (Balthazart J, Ball GF, eds), pp 43-63. Oxford: Oxford UP.

Rossi E, Morabito A, Di Rella F, Esposito G, Gravina A, Labonia V, Landi G, Nuzzo F, Pacilio C, De Maio E, Di Maio M, Piccirillo MC, De Feo G, D'Aiuto G, Botti G, Chiodini P, Gallo C, Perrone F, de Matteis A (2009) Endocrine effects of adjuvant letrozole compared with tamoxifen in hormone-responsive postmenopausal patients with early breast cancer: the HOBOE trial. J Clin Oncol 27:3192-3197. CrossRef Medline

Saldanha CJ, Tuerk MJ, Kim YH, Fernandes AO, Arnold AP, Schlinger BA (2000) Distribution and regulation of telencephalic aromatase expression in the zebra finch revealed with a specific antibody. J Comp Neurol 423:619-630. CrossRef Medline

Shiba Y, Santangelo AM, Braesicke K, Agustín-Pavón C, Cockcroft G, Haggard M, Roberts AC (2014) Individual differences in behavioral and cardiovascular reactivity to emotive stimuli and their relationship to cognitive flexibility in a primate model of trait anxiety. Front Behav Neurosci 8:137. CrossRef Medline

Sievert LL (2013) Subjective and objective measures of hot flashes. Am J Hum Biol 25: 573-580. CrossRef Medline

Sievert LL, Freedman RR, Garcia JZ, Foster JW, del Carmen Romano Soriano M, Longcope C, Franz C (2002) Measurement of hot flashes by sternal skin conductance and subjective hot flash report in Puebla, Mexico. Menopause 9:367-376. CrossRef Medline

Smejkalova T, Woolley CS (2010) Estradiol acutely potentiates hippocampal excitatory synaptic transmission through a presynaptic mechanism. J Neurosci 30:16137-16148. CrossRef Medline

Spinelli S, Pennanen L, Dettling AC, Feldon J, Higgins GA, Pryce CR (2004) Performance of the marmoset monkey on computerized tasks of attention and working memory. Cogn Brain Res 19:123-137. CrossRef Medline

Tankersley CG, Nicholas WC, Deaver DR, Mikita D, Kenney WL (1992) Estrogen replacement in middle-aged women: thermoregulatory responses to exercise in the heat. J Appl Physiol 73:1238-1245. CrossRef Medline

Tardif SD, Mansfield KG, Ratnam R, Ross CN, Ziegler TE (2011) The marmoset as a model of aging and brain disease. ILAR J 52:54-65. CrossRef Medline

Taylor GT, Manzella FM, Huffman J, Cabrera OH, Hoffman J (2017) Cognition in female rats after blocking conversion of androgens to estrogens. Horm Behav 90:84-89. CrossRef Medline

Tuscher JJ, Szinte JS, Starrett JR, Krentzel AA, Fortress AM, Remage-Healey L, Frick KM (2016) Inhibition of location estrogen synthesis in the hippocampus impairs hippocampal memory consolidation in ovariectomized female mice. Horm Behav 83:60-67. CrossRef Medline

Vahaba DM, Remage-Healey L (2015) Brain estrogen production and the encoding of recent experience. Curr Opin Behav Sci 6:148-153. CrossRef Medline

Vierk R, Glassmeier G, Zhou L, Brandt N, Fester L, Dudzinski D, Wilkars W, Bender RA, Lewerenz M, Gloger S, Graser L, Schwarz J, Rune GM (2012) 
Aromatase inhibition abolishes LTP generation in female but not in male mice. J Neurosci 32:8116-8126. CrossRef Medline

Vierk R, Brandt N, Rune GM (2014) Hippocampal estradiol synthesis and its significance for hippocampal synaptic stability in male and female animals. Neuroscience 274:24-32. CrossRef Medline

Wehrenberg U, Prange-Kiel J, Rune GM (2001) Steroidogenic factor-1 expression in marmoset and rat hippocampus: co-localization with StAR and aromatase. J Neurochem 76:1879-1886. CrossRef Medline

Wong M, Moss RL (1992) Long-term and short-term electrophysiological effects of estrogen on the synaptic properties of hippocampal CA1 neurons. J Neurosci 12:3217-3225. CrossRef Medline

Wu WW, Adelman JP, Maylie J (2011) Ovarian hormone deficiency reduces intrinsic excitability and abolishes acute estrogen sensitivity in hippocampal CA1 pyramidal neurons. J Neurosci 31:2638-2648. CrossRef Medline

Yamazaki Y, Saiki M, Inada M, Watanabe S Iriki A (2016) Sustained performance by common marmosets in a delayed matching to position task with variable stimulus presentations. Behav Brain Res 297:277-284. CrossRef Medline

Zhou L, Fester L, von Blittersdorff B, Hassu B, Nogens H, Prange-Kiel J, Jarry H, Wegscheider K, Rune GM (2010) Aromatase inhibitors induce spine synapse loss in the hippocampus of ovariectomized mice. Endocrinology 151:1153-1160. CrossRef Medline

Zhu BT, Conney AH (1998) Functional role of estrogen metabolism in target cells: review and perspectives. Carcinogenesis 19:1-27. CrossRef Medline 